\title{
The duty to speak up
}

\author{
Serena is a Cancer Research UK Advanced Clinician Scientist at the University of Cambridge. She studies mutation \\ patterns in human DNA and finds ways to make it applicable in a clinical setting. Serena is a mother of two, loves \\ music and being outdoors, and fights the forties with kung fu.
}

\section{Serena Nik-Zainal}

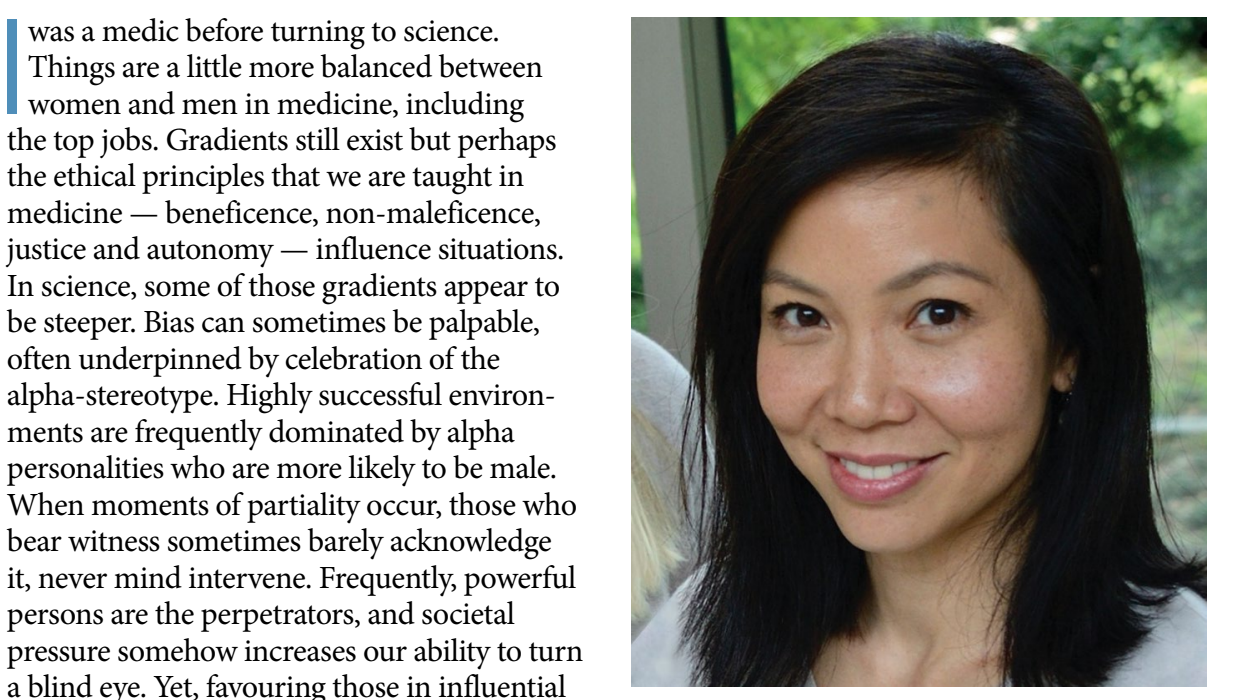
positions is a form of positive discrimination and is as equally damaging as negative discrimination, gender-related or otherwise, because it reinforces a gradient. In science, I have learned valuable lessons about trying to level such gradients.

Lesson 1: we all have a responsibility to speak up when moments of injustice occur. So did I, at one point in my career. I questioned why I was being treated differently within a group of predominantly male, collaborating peers. My concerns were dismissed. Regrettably, the pitch of the gradient of gender bias became steeper.

Lesson 2: it takes courage to speak up, and there can be consequences. The intensity of the reaction to my speaking up was severe. I missed out on a career step, a position in a high-profile grant, a nomination for something. I did not mourn those losses. Instead, I grieved for the overall message - I was valued for my contribution, but only if I remained silent. Being rewarded on the basis of merit was for those who looked the other way. So, I walked away from that situation. One or two senior colleagues, who were in the know, metaphorically patted me on the head. I received comments like 'these things happen', 'you need to keep looking successful, so keep this to yourself', and 'just focus on your science'. I found this perplexing. Surely these attitudes simply reinforce the gradients.

Lesson 3: talking to others helps.

Expressing yourself does not make you weak. and diversity at an institutional level that did not translate to how people were treated at an individual level.

Of late, institutions and funders have talked of taking a tough line on bullying, harassment, and on ensuring diversity and inclusion. It remains to be seen whether they will back their words with action when specific issues arise, or whether there will be special dispensation for influential people. The tough talk would then simply be hypocrisy. It would also be an opportunity missed. If not corrected, these mis-stepping powerful personalities go on to advisory boards, career-decision committees and grant-review panels, bringing and thus perpetuating their inherent prejudices.

Do we need a code of ethics in academia? When trying to raise issues one may come up against a misplaced ethos that legality matters most. It is a mindset that places priority on protecting an institution legally, no matter the cost, culminating in out-of-court-settlements and non-disclosure agreements that do not address issues openly and directly. A legal position however, may not equate to an ethical one. Slavery was perfectly legal once upon a time. Perhaps, if we placed more emphasis on doing the right thing, concerns about legality would not arise. Having a set of academic ethical principles that we should aspire to might increase the likelihood of people treating others the way they would expect to be treated themselves.

For now, to improve those gradients, we all have a responsibility. When we witness impropriety, we cannot shrug our shoulders and say 'it's not my problem', because then we become part of the problem; one is complicit through silence. We need to speak up. All tyranny needs to gain a foothold is for good people to remain silent.

\section{Serena Nik-Zainal}

Department of Medical Genetics, The Clinical School, University of Cambridge, Cambridge, UK. e-mail:sn206@cam.ac.uk situation and the social pressure to go with the flow was considerable. Additionally, I had a strong sense of goodwill for some of the shared past successes. So, I complied. In hindsight, it was not the right thing to do. I played a part in feeding into the hyperbole of 'awards', 'drives' and 'endeavours' for equality
Published online: 28 August 2018 https://doi.org/10.1038/s41556-018-0171-7

The author declares no competing interests. 